\title{
Pemanfaatan Framework Codeigniter Dalam Pengembangan Aplikasi Reporting Research
}

\author{
Asep Saifudin ${ }^{1}$, Meri Mayang Sari ${ }^{2}$, Asaidha Kuncoro ${ }^{3}$ \\ ${ }^{1}$ Program Studi Teknik Informatika STTIKOM Insan Unggul Cilegon, ${ }^{2,3}$ Program Studi Sistem \\ Informasi Universitas Raharja \\ Email : asep.saifudin22@ gmail.com, *2 meri.mayang@ raharja.info, asaidha@ raharja.info
}

\begin{abstract}
Abstrak
Perkembangan teknologi terus berkembang pesat. dalam bidang apapun seperti ekonomi, sosial, transportasi dan lain-lain ikut serta dalam perkembangan teknologi. Banyak konsumen menuntut perkembangan industri untuk dapat memenuhi segala kebutuhannya dengan cepat dan berkualitas, sehingga diperlukan suatu sarana yang dapat membantu dalam melaksanakan produksi kebutuhan yang dimaksud. Saat ini sistem yang berjalan masih menggunakan Microsoft Excel dalam pembuatan laporan pada bidang produksi furniture, bagian ini sangat membutuhkan suatu teknologi yang dapat mempermudah pekerjaannya secara efektif dan efisien. Dalam pembuatan laporan petugas mengalami kesulitan sehingga membutuhkan waktu yang cukup lama dan sebelum diproses harus mendapat persetujuan dari supervisor yang bertanggung jawab agar dapat diproses ke tahap selanjutnya yaitu tahap produksi. maka diperlukan suatu sistem sebagai media untuk membantu petugas dalam membuat laporan dan memudahkan dalam menyetujui laporan serta memberikan kemudahan kepada petugas dalam mencari dan menyimpan data yang telah dibuat. Framework yang digunakan dalam merancang aplikasi reporting research adalah framework CodeIgniter sebagai kerangka kerja dalam membuat sebuah sistem atau aplikasi, bahasa pemrogramannya menggunakan Javascript, CSS dan PHP. Dengan adanya aplikasi ini diharapkan sistem dapat memberikan rasa nyaman dalam bekerja dan kemudahan dalam pembuatan laporan.
\end{abstract}

Kata kunci : framework CodeIgniter, reposting research, laporan, aplikasi

\begin{abstract}
Technological developments continue to grow rapidly. in any field such as economic, social, transportation and others participate in technological developments. Many consumers demand industrial development to be able to meet all their needs quickly and with quality, so we need a facility that can assist in carrying out the production of the intended needs. Currently the running system is still using Microsoft Excel in making reports in the furniture production sector, this section really needs a technology that can facilitate its work effectively and efficiently. In making reports, officers experience difficulties so that it takes a long time and prior to processing, they must obtain approval from the supervisor in charge so that they can be processed to the next stage, namely the production stage. then we need a system as a medium to assist officers in making reports and make it easier to approve reports and provide convenience to officers in finding and storing data that has been made. The framework used in designing reporting research applications is the CodeIgniter framework as a framework for creating a system or application, the programming language uses Javascript, CSS and PHP. With this application, it is hoped that the system can provide a sense of comfort in working and ease of reporting.
\end{abstract}

Keywords: CodeIgniter framework, reporting research, reports, applications 


\section{PENDAHULUAN}

Perkembangan teknologi terus berkembang pesat. Dalam bidang apapun seperti ekonomi, sosial, transportasi dan banyak lagi lainnya yang berusaha mendapatkan teknologi ini. Untuk memenuhi keinginan konsumen yang terus berubah dari waktu ke waktu, perusahaan harus melakukan riset produk. Sehingga diperlukan perhitungan atau taksiran dalam laporan mengenai bahan yang dibutuhkan, biaya yang dibutuhkan, dan sebagainya. Yang harus ditulis secara detail dan jelas kedalam laporan. Pelaporan masih menggunakan Microsoft Word dan Microsoft Excel, untuk melakukan perhitungan antara satu dengan yang lainnya harus disisipkan terlebih dahulu untuk menghasilkan laporan yang membutuhkan banyak waktu. Serta membutuhkan ketelitian agar perhitungan rumus tidak salah saat mengetik. Sehingga diperlukan suatu sistem sebagai media untuk membantu petugas dalam membuat laporan dan memudahkan dalam menyetujui laporan serta memudahkan petugas untuk mencari dan menyimpan data yang telah dibuat.

\section{Dasar Teroi yang terkait dengan judul penelitian Framework}

(Praba 2018), berpendapat bahwa Framework dapat diartikan sebagai kumpulan potongan program yang disusun atau diatur sedemikian rupa sehingga dapat digunakan untuk membantu membuat aplikasi yang diunduh tanpa harus membuat semua kode dari awal

\section{CodeIgniter}

(Supono and Putratama 2016), mengemukakan bahwa CodeIgniter adalah framework PHP dengan konsep MVC, dimana model berhubungan dengan database, view berhubungan dengan tampilan HTML dan controller berhubungan dengan logic programming.

\section{Aplikasi}

(Rahayu et al., 2019), mengemukakan bahwa Aplikasi adalah suatu kegunaan dalam komputer, instruksi atau pernyataan yang disusun sedemikian rupa sehingga komputer dapat mengolah masukan menjadi keluaran.

\section{Pengembangan}

(H. Aras Solong and Asri Yadi 2021), berpendapat bahwa Pengembangan adalah me,perbaiki pekerjaan yang sekarang maupun yang akan datang dengan memberikan informasi, mempengauhi sikap akan menambah kecakapan. Dengan kata lain pengembangan adalah setiap kegiatan yang dimaksudkan untuk mengubah perilaku yang terdiri dari pengetahuan, kecakapan dan sikap. Atau dengan istilah bahwa pengembangan menunjukkan pada suatu kegiatan yang menghasilkan suatu alat atau cara yang baru, dimana selama kegiatan tersebut terus menerus dilakukan. Pengembangan adalah pembaharuan, yaitu melakukan upaya untuk menjadikan sesuatu lebih sesuai dengan kebutuhan, menjadi lebih baik dan lebih bermanfaat.

\section{Penelitian Sebelumnya}

1. Tyowati \& Irawan, 2017 "Implementasi Framework CodeIgniter untuk Pengembangan Websitepada Dinas Perkebunan Provinsi Kalimantan Tengah". Implementasi Framwork CodeIgniter ini bertujuan untuk menyampaikan informasi profil, harga komoditas, mitra usaha, pengumuman, agenda resmi, galeri kegiatan serta file yang diunduh. Dengan menggunakan metode analisis pieces. Dengan adanya sistem ini pengunjung dapat dengan mudah dalam mencari informasi mengenai harga komoditas, pengumuman dan agenda pelayanan, mendownload file perkebunan serta dapat melihat foto dan video kegiatan serta fitur-fitur yang memudahkan pengunjung dalam mencari. informasi dan fitur yang diperlukan lebih banyak dari media blogspot sebelumnya

2. Rohimat, 2016 "Penggunaan Framework Codeigniter Pada Aplikasi Web Perhitungan Rencana Anggaran Biaya Pembangunan Rumah". tujuan dari dibuatnya sistem ini agar 
dapat menghitung anggaran pembangunan rumah yang dapat membantu masyarakat sekaligus sebagai alternatif perhitungan perencanaan dalam membangun rumah. Dalam hal ini penulis menggunakan hubungan sebab akibat (eksperimen) dan studi pustaka dengan mengumpulkan data-data yang berhubungan dengan materi pendukung dan penelitian. Framework yang digunakan adalah CodeIgniter, sebagai pengembangan aplikasi dalam pembuatan suatu sistem dan bahasa pemrograman yang digunakan HyperText Markup Language (HTML), Hypertext Processor (PHP), Cascading Style Sheets (CSS) dan Java Script serta MySQL sebagai penyimpanan sistem basis data. Sistem ini mampu menghitung anggaran dalam membangun rumah yang mampu menampilkan laporan rencana pembangunan yang hendak dibangun.

3. Padmanaba et al., 2020, "Komparasi Penggunaan Framework Codeigniter VS PHP Native Pada Sistem Informasi Manajemen Surat Sekretariat DPRD Pemalang”. Penelitian ini membahaas mengenai perbandingan antara Codeigniter Framework atau PHP Native dalam pembuatan Sistem Informasi Manajemen Surat, dan menghasilkan bahwa Framework CodeIgniter lebih baik dari PHP Native dalam hal kinerja dan direkomendasikan untuk digunakan oleh pengguna, sedangkan PHP Native lebih sederhana dalam pengkodean sistem, dapat direkomendasikan untuk programmer tingkat lanjut dan bukan untuk kerja tim, karena beberapa variabel hanya programmer yang mengetahui dalam membuat sistem ini, sehingga tidak cocok untuk bekerja tim.

\section{METODE PENELITIAN}

2.1. Metode Penelitian

2.1.1. Metode Pengumpulan Data

Dalam metode ini terdapat 3 tahapan, yaitu: 1) Metode Observasi, dalam metode ini peneliti menganalisis permasalahan yang ada dengan mengamati secara langsung proses pelaporan bahan material pada bidang produksi furniture PT Talenta Anugrah Pratama. 2) metode wawancara (interview), peneliti menggunakan metode ini untuk memenuhi informasi penelitian, berusaha mendapatkan data dengan bertanya langsung kepada pihak-pihak yang bersangkutan. 3) kepustakaan (library research) informasi yang berkaitan dengan masalah yang akan disusun, selain melakukan observasi dan wawancara, peneliti juga melakukan studi kepustakaan yaitu metode pengumpulan data yang dilakukan dengan mencari melalui berbagai situs internet, jurnal dan artikel

\subsubsection{Metode Analisa Sistem}

Analisis sistem yang digunakan dalam penelitian ini untuk merancang sistem menggunakan metode SWOT yang artinya menganalisis kekuatan, kelemahan, peluang, dan ancaman yang secara sistematis dapat membantu mengidentifikasi faktor eksternal $(\mathrm{O}$ dan $\mathrm{T}$ ) maupun internal ( $\mathrm{S}$ dan $\mathrm{W}$ ) perusahaan. dalam membuat aplikasi reporting research. 
Tabel 1. Analisa SWOT

\begin{tabular}{|c|c|}
\hline Strength & Weakness \\
\hline $\begin{array}{l}\text { 1. Proses pembuatan laporan penelitian } \\
\text { terampil, menjadikan hasil bahan } \\
\text { produk hasil tejiamin kualitasnya } \\
\text { sesuai dengan visi yang telah dijaga } \\
\text { dengan baik selama ini } \\
\text { 2. Laporan penelitian yang dihasilkan } \\
\text { terstruktur dan mudah dibaca } \\
\text { 3. Data disimpan dalam bentuk digital } \\
\text { atau tidak }\end{array}$ & $\begin{array}{l}\text { 1. Masih terdapat kesalahan } \\
\text { yang dapat ditimbulkan oleh } \\
\text { karyawan karena tidak } \\
\text { menggunakan aplikasi atau } \\
\text { sistem informasi khusus, } \\
\text { kecuali melalui Microsoft } \\
\text { Office }\end{array}$ \\
\hline Opportunities & Treats \\
\hline $\begin{array}{l}\text { 1. Produk hasil dari laporan penelitian } \\
\text { material mendapatkan penilaian yang } \\
\text { baik di mata konsumen } \\
\text { 2. biaya yang dikeluarkan untuk } \\
\text { produksi dapat ditekan agar tidak } \\
\text { melambung }\end{array}$ & $\begin{array}{l}\text { 1. Banyak pesaing melakukan } \\
\text { hal yang sama }\end{array}$ \\
\hline
\end{tabular}

\subsubsection{Metode Perancangan Sistem}

Perancangan sistem yang digunakan pada penelitian ini dilakukan dengan tahapan pembuatan UML (unified Modeling Language) menggunakan aplikasi visual paradigma untuk UML 16.1 edisi enterprise, dan untuk perancangan sistem menggunakan bahasa pemrograman PHP, dan database yang digunakan adalah MySQL untuk memudahkan peneliti dalam membuat sebuah sistem.

\subsubsection{Metode Pengujian Sistem}

Dalam penelitian ini metode pengujian sistem, menggunakan pengujian blackbox, dimana ketika melakukan pengujian pada sistem dapat dipahami karena bersifat fungsional. Kelebihan dari metode blackbox testing adalah mudah dilakukan karena berfokus pada input dan output, membutuhkan waktu yang lebih sedikit untuk membuat dan menguji skenario, mengikuti sudut pandang "user" dan bukan dari sudut pandang "developer" sehingga hasil pengujian netral (sistem berfungsi atau tidak).

\section{HASIL DAN PEMBAHASAN}

Setelah melakukan proses penelitian dan analisa pada sistem yang berjalan pada produksi furniture PT Talenta Anugrah Pratama, , langkah selanjutnya akan membahas perancangan sistem yang akan dibangun. Yang bertujuan untuk membantu percepat proses tersebut dan untuk penyimpanan data yang disimpan ke database untuk mempermudahkan karyawan yang terlibat dalam pencarian data. Sehingga tahapan proses selanjutnya akan membahas perancangan sistem yang akan diusulkan untuk memenuhi kebutuhan dan memperbaiki pada sistem yang sebelumnya dengan menggunakan aplikasi Visual Paradigm for UML 16.1 Community Edition yang digambarkan dalam bentuk Use Case Diagram dan Activity Diagram. 


\subsection{Usecase diagram diusulkan}

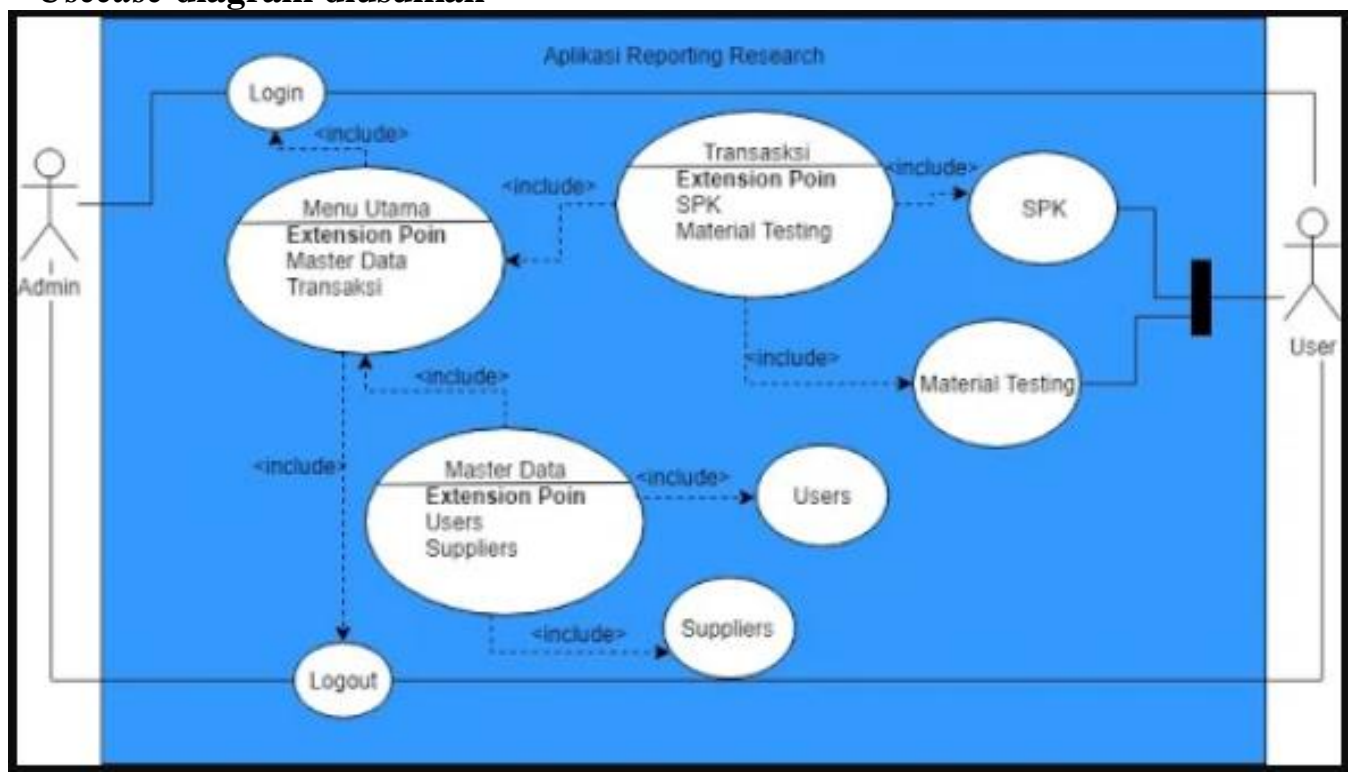

Gambar 1 usecase diusulkan berikut:

Prosedur proses Pengembangan Aplikasi Reporting Research disusulkan adalah sebagai

1. Untuk dapat mengakses aplikasi admin atau user harus login terlebih dahulu

2. Didalam menu Users terdapat data pengguna yang dapat menambahkan data baru, merubah, dan menghapus data.

3. Didalam menu form data bahan baku user dapat menambahkan, editing, penghapusan, dan pencarian data bahan baku.

4. Didalam menu Suppliers berisi data supplier yang sudah ada, dan dapat ditambah data baru, mnegubah dan menghapus data.

5. Didalam menu SPK terdapat data SPK yang sudah ada, data dipisahkan sesuai masingmasing bagian yang telah menyatakan persetujuan pada data yang telah dibuat, user dapat menambah data baru, merubah, menghapus data, serta mengirim ulang pesan elektronik ke bagian yang dimaksud.

6. Menu Material Testing terdiri dari beberapa sub menu dengan form template yang berbeda, pada setiap sub menu terdapat data Material Testing sesuai dengan template masingmasing, user dapat menambah data baru, merubah, menghapus data, serta mengirim ulang elektronik pesan ke bagian terakhir yang telah diatur sebelumnya oleh sistem. 


\subsection{Activity User yang diusulkan}

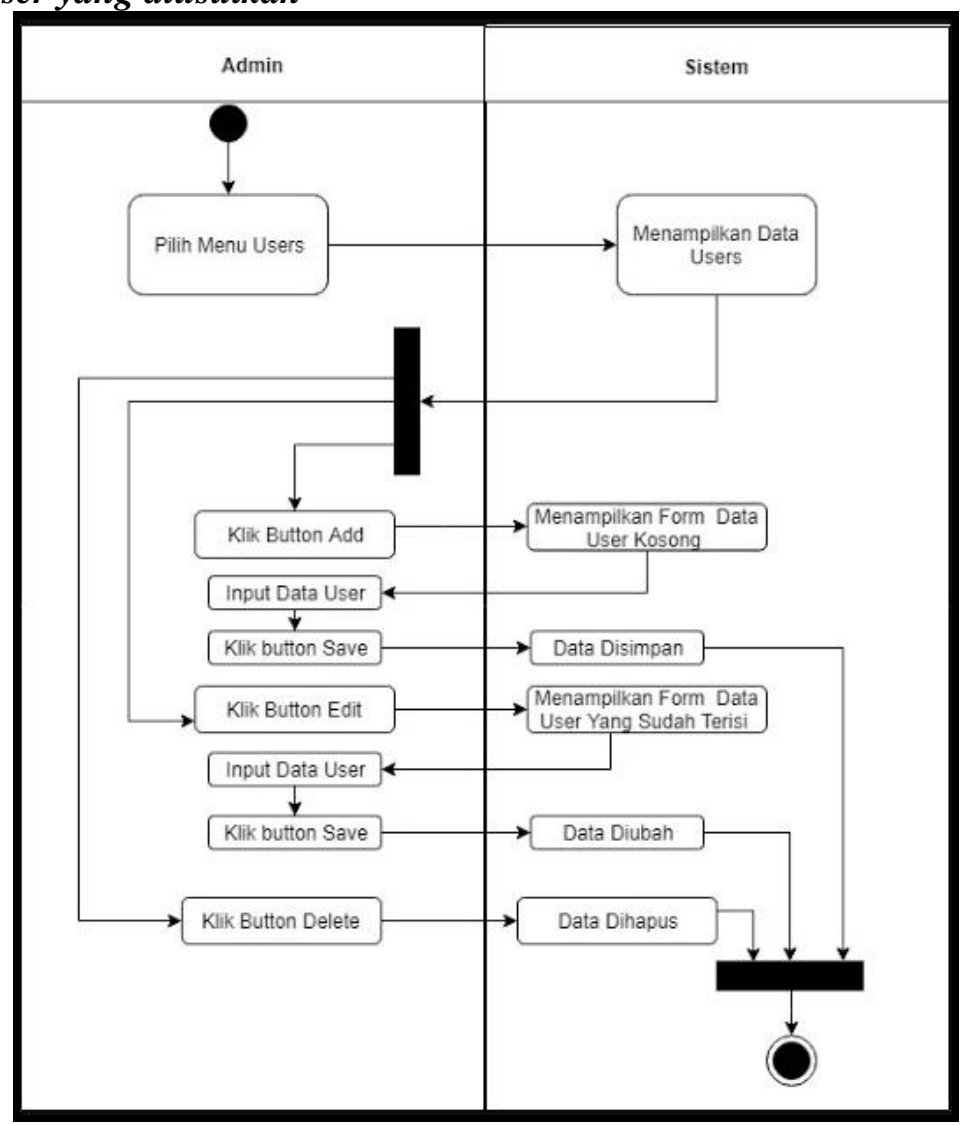

Gambar 2 activity user diusulkan

Prosedur proses Pengembangan Aplikasi Reporting Research disusulkan adalah sebagai berikut:

1. Admin pilih menu user agar dapat menampilkan data user.

2. Pada menu user terdapat button add untuk menampilkan form data user kosong, setelah terbuka maka user harus input data user dan save untuk menyimpan data.

3. pada button edit akan menapilkan form data user yang sudah terisi, dan user dapat merubah data yang sebelumnya kemudian save agar data berubah.

4. Pada button delete digunakan untuk mengahpus data yang dirasa tidak penting. 


\subsection{Rancangan Program}

\section{Tampilan Halaman Login}

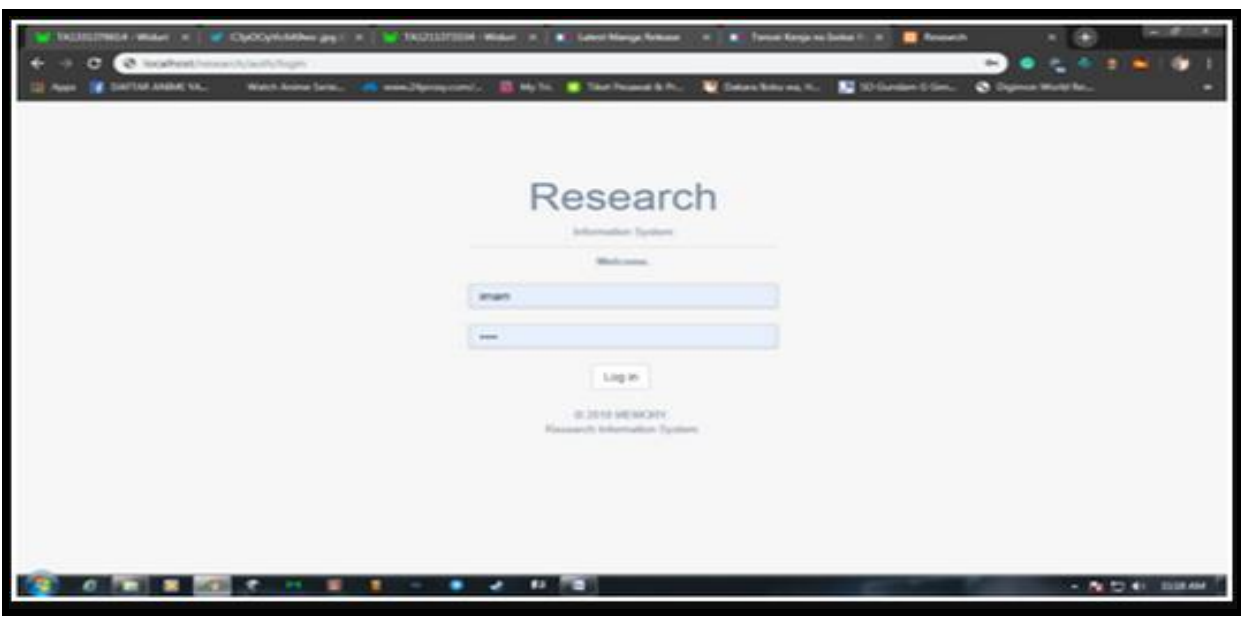

Gambar 3 halaman login

Gambar 3 menampilkan menu login sebelum memasukin dashboard pada sistem

\section{Tampilan Halaman User}

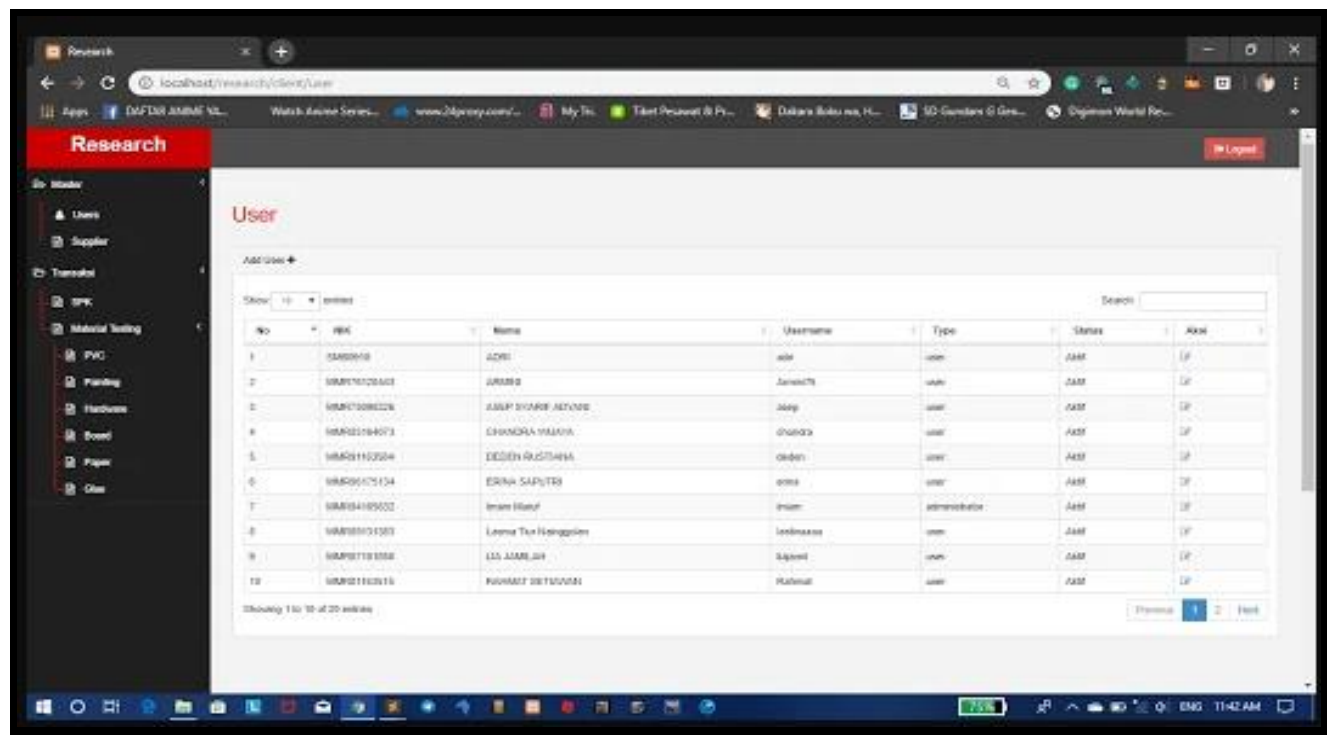

Gambar 4 halaman user

Gambar 4menampilkan seluruh user yang telah terdaftar dan tersimpan pada aplikasi. 


\section{Tampilan Halaman Supplier}

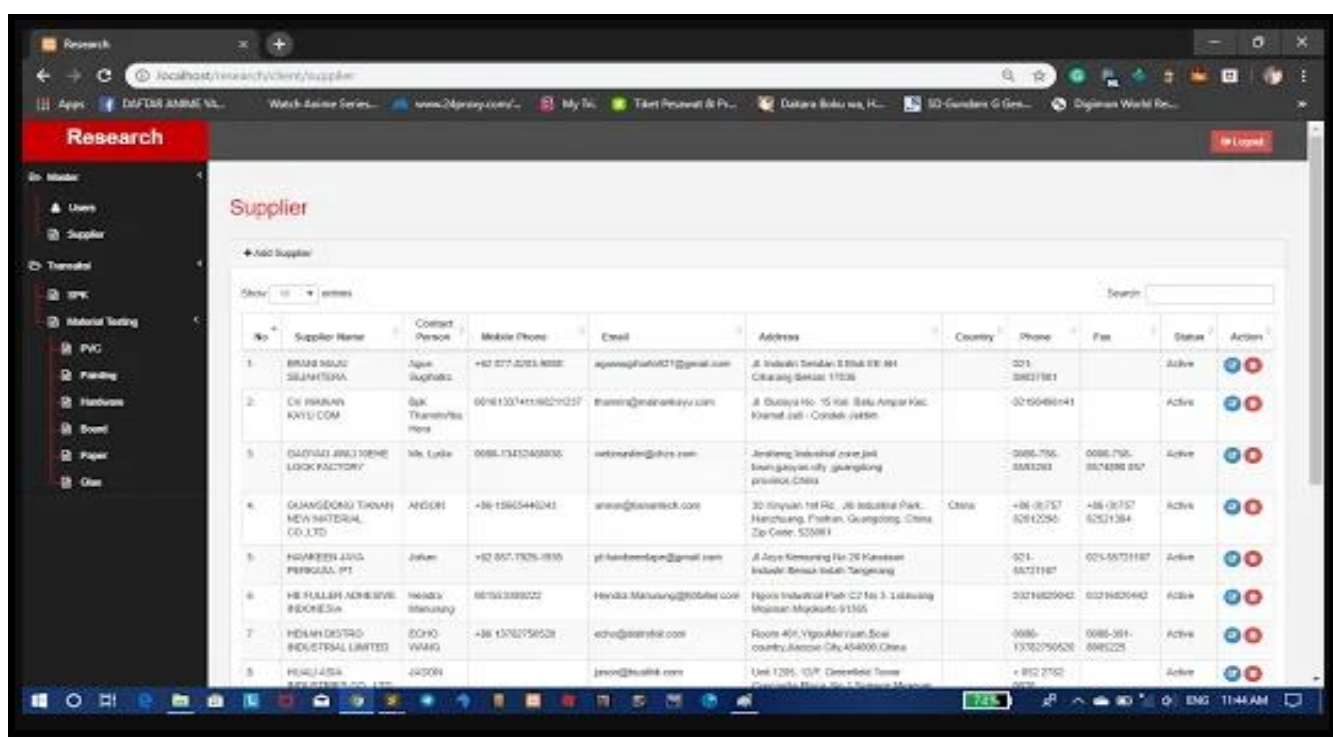

Gambar 5 halaman supplier

Gambar 5 menampilkan data-data supplier yang sudah disimpan sebelumnya.

\section{Tampilan Halaman Web Viw PDF Data Laporan SPK}

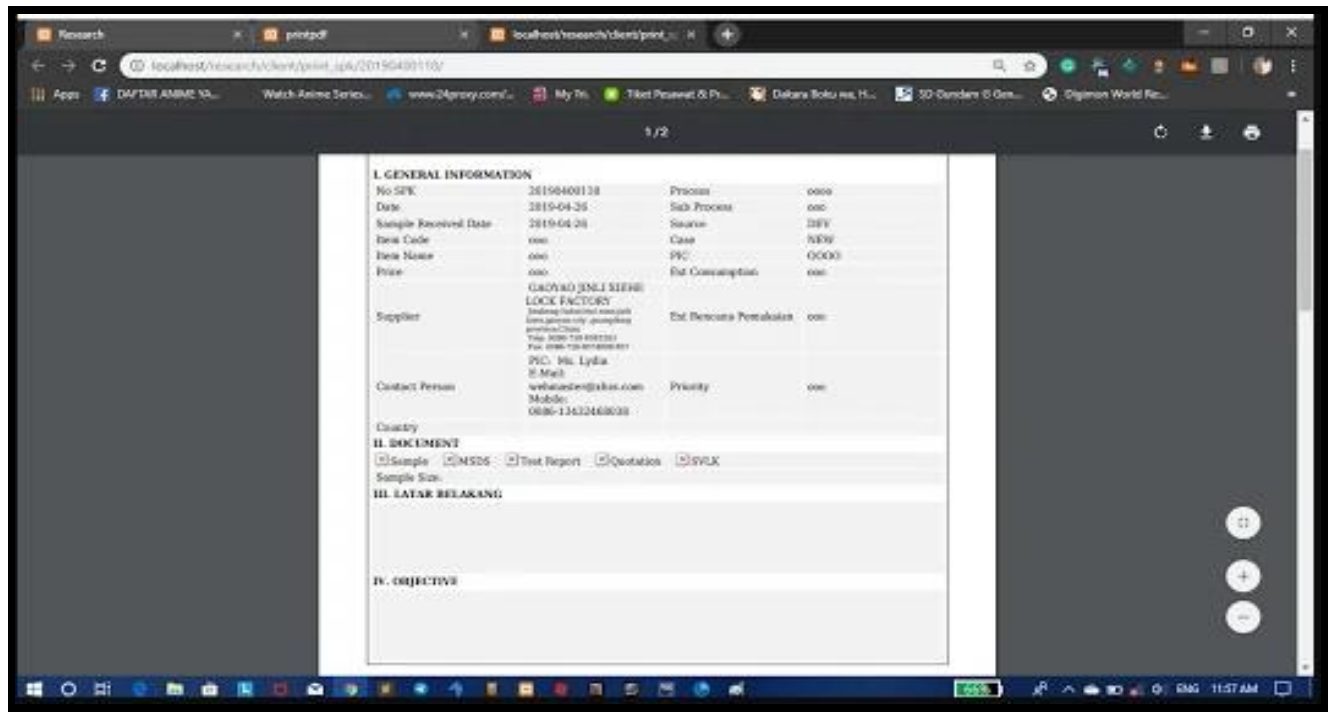

Gambar 6 Halaman Web View PDF Data Laporan SPK

Gambar 6 memanpilkan hasil data laporan SPK berbentuk PDF yang dapat di download maupun di print langsung. 


\section{Tampilan Halaman Persetujuan Laporan SPK}

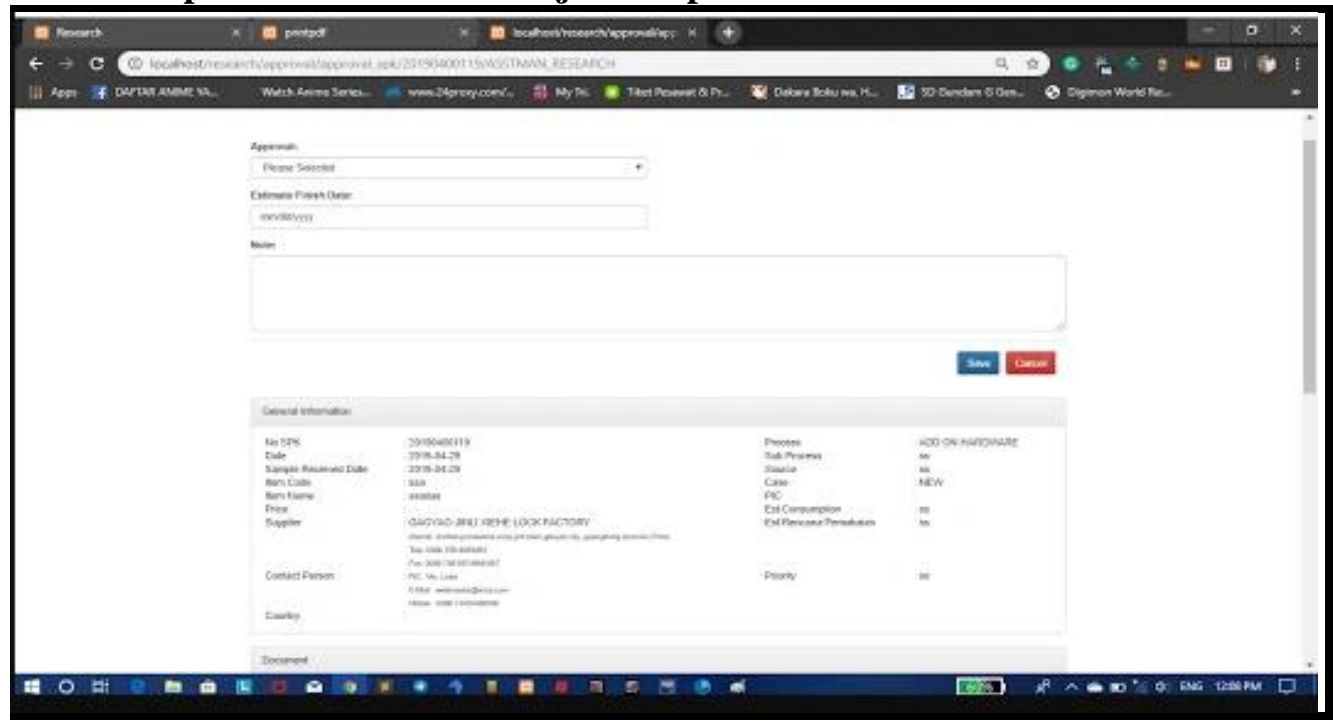

Gambar 7 Halaman Persetujuan Laporan SPK

Gambar 7 menampilkan persetujuan atas laporan SPK

\section{KESIMPULAN}

Pemanfaatan Framework Codeigniter dalam Pembuatan Aplikasi Reporting Research memiliki manfaat dapat membantu petugas dalam membuat laporan tanpa harus menginput rumus karena aplikasi ini dilengkapi dengan rumus-rumus yang ada pada Microsoft Excel untuk mendapatkan sistem yang dapat menyimpan data dengan rapi, mengurangi resiko kesalahan, dan mempercepat petugas dalam membuat laporan.

\section{SARAN}

Dengan semakin majunya perkembangan teknologi diharapkan sistem yang dibuat dapat dikembangkan kembali menjadi sistem yang lebih canggih sehingga meningkatkan keakuratan pengguna dalam memproses pembautan laporan guna menghindari resiko kehilangan data dan kesalahan.

\section{DAFTAR PUSTAKA}

[1] Praba, A. D. (2018). Implementasi Model View Controller Dengan Framework Codeigniter Pada Perpustakaan. In Indonesian Journal on Software Engineering (IJSE) (Vol. 4, Issue 1, pp. 93-97). https://doi.org/10.31294/ijse.v4i1.6393

[2] Supono., \& Putratama, V. 2018. Pemrograman Web Dengan Menggunakan Php Dan Framework Codeigniter. Yogyakarta: Deepublish

[3] Rahayu, W. I., Fajri, R. R., \& Hambali, P. (2019). Rancang Bangun Aplikasi Penentuan Dan Share Promo Produk Kepada Pelanggan Dari Website Ke Media Sosial Berbasis Desktop. Kreatif. 
[4] Tyowati, S., \& Irawan, R. (2017). Implementasi Framework Codeignter Untuk Pengembangan Website Pada Dinas Perkebunan Provinsi Kalimantan Tengah. In Jurnal SAINTEKOM (Vol. 7, Issue 1, p. 67). https://doi.org/10.33020/saintekom.v7i1.22

[5] Rohimat. (2016). Penggunaan Framework Codeigniter Pada Aplikasi Web Perhitungan Rencana Anggaran Biaya Pembangunan Rumah. MASITIKA, 1(0). http://journal.widyadharma.ac.id/index.php/masitika/article/view/148

[6] Padmanaba, A., Erna, K. N., \& Andayati, D. (2020). Komparasi Penggunaan Framework Codeigniter Vs Php Native Pada Sistem Informasi Manajemen Surat Sekretariat DPRD Pemalang. Scriptorium, 8(1), 1-6

[7] H. Aras Solong, M. S., \& Asri Yadi, M. P. (2021). Kajian Teori Organisasi Dan Birokrasi Dalam Pelayanan Publik. Deepublish. 